\title{
Direct In Situ TEM Visualization and Insight into the FacetDependent Sintering Behaviors of Gold on TiO2
}

Yuan, Wentao; Zhang, Dawei; Ou, Yang; Fang, Ke; Zhu, Beien; Yang, Hangsheng; Hansen, Thomas W.; Wagner, Jakob Birkedal; Zhang, Ze; Gao, Yi

Total number of authors:

11

Published in:

Angewandte Chemie

Link to article, DOI:

10.1002/ange.201811933

Publication date:

2018

Document Version

Peer reviewed version

Link back to DTU Orbit

Citation (APA):

Yuan, W., Zhang, D., Ou, Y., Fang, K., Zhu, B., Yang, H., Hansen, T. W., Wagner, J. B., Zhang, Z., Gao, Y., \& Wang, Y. (2018). Direct In Situ TEM Visualization and Insight into the FacetDependent Sintering Behaviors of Gold on $\mathrm{TiO}_{2}$. Angewandte Chemie, 130(51), 17069-17073. https://doi.org/10.1002/ange.201811933

\section{General rights}

Copyright and moral rights for the publications made accessible in the public portal are retained by the authors and/or other copyright owners and it is a condition of accessing publications that users recognise and abide by the legal requirements associated with these rights.

- Users may download and print one copy of any publication from the public portal for the purpose of private study or research.

- You may not further distribute the material or use it for any profit-making activity or commercial gain

- You may freely distribute the URL identifying the publication in the public portal 


\title{
Direct in situ TEM visualization and insight of the facet-dependent sintering behaviours of $\mathrm{Au}$ on $\mathrm{TiO}_{2}$
}

\author{
Wentao Yuan, ${ }^{[a]+}$ Dawei Zhang, ${ }^{[b]+}{ }^{\dagger}$ Yang Ou, ${ }^{[a]}$ Ke Fang, ${ }^{[a]}$ Beien Zhu, ${ }^{*[b]}$ Hangsheng Yang, ${ }^{[a]}$ Thomas \\ W. Hansen, ${ }^{[c]}$ Jakob B. Wagner, ${ }^{[c]}$ Ze Zhang, ${ }^{[a]}$ Yi Gao*[b] and Yong Wang ${ }^{*[a]}$
}

\begin{abstract}
To prevent sintering of supported nanocatalysts is an important issue in nanocatalysis because the size of a nanoparticle (NP) is a critical parameter for its catalytic reactivity. A possible way to increase the durability of a nanocatalyst is to choose a suitable support. However, whether the metal-support interaction (MSI) promote or prevent the sintering process has not been fully identified due to the lack of confirmed experimental evidence. Herein, by combining spherical aberration corrected scanning transmission electron microscopy with environmental transmission electron microscopy, we report on completely different sintering behaviours of $\mathrm{Au}$ nanoparticles on distinct anatase $\mathrm{TiO}_{2}$ surfaces. The full in situ sintering processes of Au nanoparticles was visualized on $\mathrm{TiO}_{2}(101)$ surface, which couples the Ostwald ripening and particle migration coalescence. In contrast, no sintering of Au nanoparticles on $\mathrm{TiO}_{2}$ anatase (001) surface was observed under the same conditions. This facet-dependent sintering mechanism is fully explained by the density function theory calculations that the strong metal-support interactions highly increase the diffusion barriers of nanoparticles and adatoms, which prevent the sintering process. Our work not only offers the direct evidence of the important role of supports in the sintering process, but also provides insightful information for the design of sintering-resistant nanocatalysts.
\end{abstract}

Metal nanoparticles (NPs) supported on oxide are of great importance in many industrial chemical processes as heterogeneous catalysts ${ }^{[1]}$. One of the key parameters controlling the activity is the size of the NP[2]. For example, Au NP will lose its reactivity rapidly when the diameter increases. However, many reactions take place at elevated temperatures, in which the highly dispersed nanocatalysts with high surface energies are prone to sintering and thereby lose activity. ${ }^{[3]}$ Therefore, understanding the sintering mechanism of supported catalysts is of considerable importance in nanoscience and nanocatalysis research. Two mechanisms are generally considered for the sintering of nanoparticles: Ostwald ripening (OR), which involves the migration of single atoms or small atomic clusters from smaller particles to larger particles; particle migration and coalescence (PMC), which involves the Brownian-like motion and coalesce of particles. ${ }^{[3]}$ Tremendous efforts have been devoted to studying the two sintering mechanisms of supported catalysts. ${ }^{[3,4]}$ Among these studies, the effect of the metal-support interaction (MSI) on

[a] Dr. W. Yuan, Y. Ou, K. Fang, Prof. H. Yang, Prof. Z. Zhang and Prof. Y. Wang

State Key Laboratory of Silicon Materials, School of Materials

Science and Engineering, Zhejiang University, Hangzhou 310027, (China)

E-mail: yongwang@zju,edu.cn.

[b] Dr. D. Zhang, Dr. B. Zhu and Prof. Y. Gao

Division of Interfacial Water and Key Laboratory of Interfacial

Physics and Technology, Shanghai Institute of Applied Physics,

Chinese Academy of Sciences, Shanghai 201800 (China)

E-mail:zhubeien@sinap.ac.cn gaoyi@sinap.ac.cn

[c] Dr. T. W. Hansen and Prof. J. B. Wagner

Center for Electron Nanoscopy, Technical University of Denmark, DK-2800, Kgs. Lyngby, (Denmark)

† These authors contributed equally to this work.

Supporting information for this article is given via a link at the end of the document. the sintering behavior is a hot topic and has been extensively discussed. ${ }^{[3-5]}$ Strong $\mathrm{MSI}$ is considered to prevent PMC by stabilizing the supported nanoparticle, however, it is also argued that it could promote the OR by decreasing the activation energy of ripening. Thus, how MSI would affect the sintering process has not been fully identified, which becomes a major obstacle to the design of sintering-resistant nanocatalysts. $\left.{ }^{[4 a, 5 b}, 6\right]$

To address this issue, direct experimental evidence linking the sintering behavior to $\mathrm{MSI}$ is necessary and demanding. As an emerging technology for sintering study, in situ transmission electron microscopy (TEM) [5a, 7] could visualize sintering processes at the atomic level, which is extremely crucial for unveiling the underlying mechanism. Exciting advances have been reported by in situ TEM in several supported catalyst systems, for instance, $\mathrm{Pt} / \mathrm{Al}_{2} \mathrm{O}_{3}{ }^{\left[{ }^{[\mathrm{a}]},\right.} \mathrm{Cu} / \mathrm{SiO}_{2}{ }^{[7 \mathrm{~g}]}, \mathrm{Ni} / \mathrm{MgAl}_{2} \mathrm{O}_{4}{ }^{[7]}$, etc. However, these studies focus on either determining the dominating sintering mechanism by statistical analysis of particle size evolution, or exploring the dynamic response of sintering behavior to environmental and support change, mostly from top view. The atomic-scale information of the interface between metal and support (from side view) during sintering is missing although such information is critical for the complete understanding of MSIdependent sintering mechanisms.

In this article, combining spherical aberration corrected scanning transmission electron microscopy (STEM) with environmental transmission electron microscopy (ETEM), the sintering behaviours of Au nanoparticles on different $\mathrm{TiO}_{2}$ anatase crystal planes have been unveiled at the atomic level. Our ETEM observation provides visualizations of complete sintering processes, involving both the OR mechanism and the PMC mechanism, of Au NPs on the $\mathrm{TiO}_{2}$ anatase (101) surface. Meanwhile, the resistance of sintering of Au NPs was observed on the $\mathrm{TiO}_{2}$ anatase (001) surface. Atomic TEM images of the interface structures show clear unwetting and wetting behaviours of $\mathrm{Au}$ NPs on these two surfaces, which links the different sintering behaviours directly to the different MSIs. Furthermore, density function theory (DFT) calculations confirmed that the facet-dependent sintering behavior is caused by the different adsorption and diffusion behaviours of $\mathrm{Au}$ on different $\mathrm{TiO}_{2}$ facets.

The high angle annular dark field (HAADF) STEM analysis were performed in an FEI Titan G2 80-300 ST TEM (300 kV), equipped with a spherical aberration corrector. The TEM analysis and in situ observation of sintering behaviours were carried out in a Hitachi H9500 ETEM, operated at $300 \mathrm{kV}$. To examine the facetdependent sintering behaviours, well-defined $\mathrm{Au}-\mathrm{TiO}_{2}$ (101) and $\mathrm{Au}-\mathrm{TiO}_{2}$ (001) model catalysts were prepared by loading $\mathrm{Au}$ nanoparticles (diameter: $\sim 4-8 \mathrm{~nm}$ ) on two typical anatase $\mathrm{TiO}_{2}$ supports $\left[\mathrm{TiO}_{2}-(101)\right.$ and $\left.\mathrm{TiO}_{2}(001)\right]$, through impregnation and in situ annealing methods. The $\mathrm{TiO}_{2}-(101)$ support is bipyramidal $\mathrm{TiO}_{2}$ nanocrystals (Figure 1a), which are dominated by $\{101\}$ surfaces (Figures 1e,1f, S1, S2 and S4; percentage of $\{101\}$ area: $>98 \%$ ); The $\mathrm{TiO}_{2}-(001)$ support is $\mathrm{TiO}_{2}$ nanosheets (Figure 1c), which are mainly exposed by $\{001\}$ surfaces (Figures $1 \mathrm{~h}, 1 \mathrm{i}, \mathrm{S1}$, S3 and S4; percentage of $\{001\}$ area: $>80 \%)$. Therefore, by loading Au NPs on these two supports, most Au NPs located at the (101) (Au-TiO 2 (101) catalysts) and (001) $\left(\mathrm{Au}-\mathrm{TiO}_{2}(001)\right.$ catalysts) surfaces, as evidenced by Figure S5. The typical Au$\mathrm{TiO}_{2}$ catalysts are shown in Figure $1 \mathrm{~b}\left[\mathrm{Au}-\mathrm{TiO}_{2}(101)\right]$ and Figure 1d $\left[\mathrm{Au}-\mathrm{TiO}_{2}(001)\right]$. The 3D visualizations and more details of these samples can be found in Figures S1-S4 and Movies S1-S4. 
Firstly, the interface structures of $\mathrm{Au}-\mathrm{TiO}_{2}$ (101) and $\mathrm{Au}-\mathrm{TiO}_{2}$ (001) model nanocatalysts were investigated. Most observed Au$\mathrm{TiO}_{2}$ (101) interfaces (17 among 20, $85 \%$ ) show incoherent structures with random orientation relationships. A typical HAADF-STEM image of the $\mathrm{Au}-\mathrm{TiO}_{2}$ (101) interface is shown in Figure 1g, viewing along $\mathrm{TiO}_{2}[010]$ direction. A round-shape $\mathrm{Au}$ $\mathrm{NP}$ with a diameter of $\sim 4.8 \mathrm{~nm}$ locates on $\mathrm{TiO}_{2}$ (101) surface, and the interface does not show a preferential relationship. The (101) and (004) crystal planes of $\mathrm{TiO}_{2}$ can be clearly identified, with interplanar spacings of $0.352 \mathrm{~nm}$ and $0.238 \mathrm{~nm}$, respectively. ${ }^{[8]}$ The contacting interface is very small and the projection length of the interface is $\sim 2.5 \mathrm{~nm}$. The unwetting behavior shows a weak MSI between the Au NPs and the $\mathrm{TiO}_{2}$ (101) surface. To illustrate intrinsic interfacial contact and get rid of the effect of size difference, we choose the ratio of interfacial length to diameter (IL/D) as a reference criterion. Several samples were further checked and the average IL/D is approximate 0.49 in a range from 0.44 to 0.58 .

Different from Au- $\mathrm{TiO}_{2}$ (101), most observed $\mathrm{Au}-\mathrm{TiO}_{2}$ (001) interfaces (15 among 20, $75 \%$ ) have a preferential contacting relationship that $\mathrm{TiO}_{2}$ (001) shares the plane with $\mathrm{Au}$ (111). A typical TEM image of the $\mathrm{Au}-\mathrm{TiO}_{2}(001)$ interface is shown in Figure 1j. The $\mathrm{TiO}_{2}$ (002) lattice spacings are $0.475 \mathrm{~nm}$, and the $\mathrm{Au}(111)$ lattice spacings are $0.236 \mathrm{~nm}$. Compared with $\mathrm{Au}-\mathrm{TiO}_{2}$ (101) catalysts, the $\mathrm{Au}-\mathrm{TiO}_{2}$ (001) catalyst has a relatively larger interface, and the IL/D is 0.82 (Figure $1 \mathrm{~b}$ ), much larger than that of the $\mathrm{Au}-\mathrm{TiO}_{2}$ (101) interface (0.52, Figure 1a). The statistical analysis also shows the average IL/D ratio of the $\mathrm{Au}-\mathrm{TiO}_{2}(001)$ interface is 0.92 (in a range of $0.80-0.96$ ), larger than that of Au$\mathrm{TiO}_{2}$ (101) interface (0.49). The different interface structures give direct evidence, that $\mathrm{Au}$ NPs attach more tightly on $\mathrm{TiO}_{2}(001)$ surface than on $\mathrm{TiO}_{2}$ (101) surface, which is consistent with previous theoretical prediction in literature..$^{[9]}$
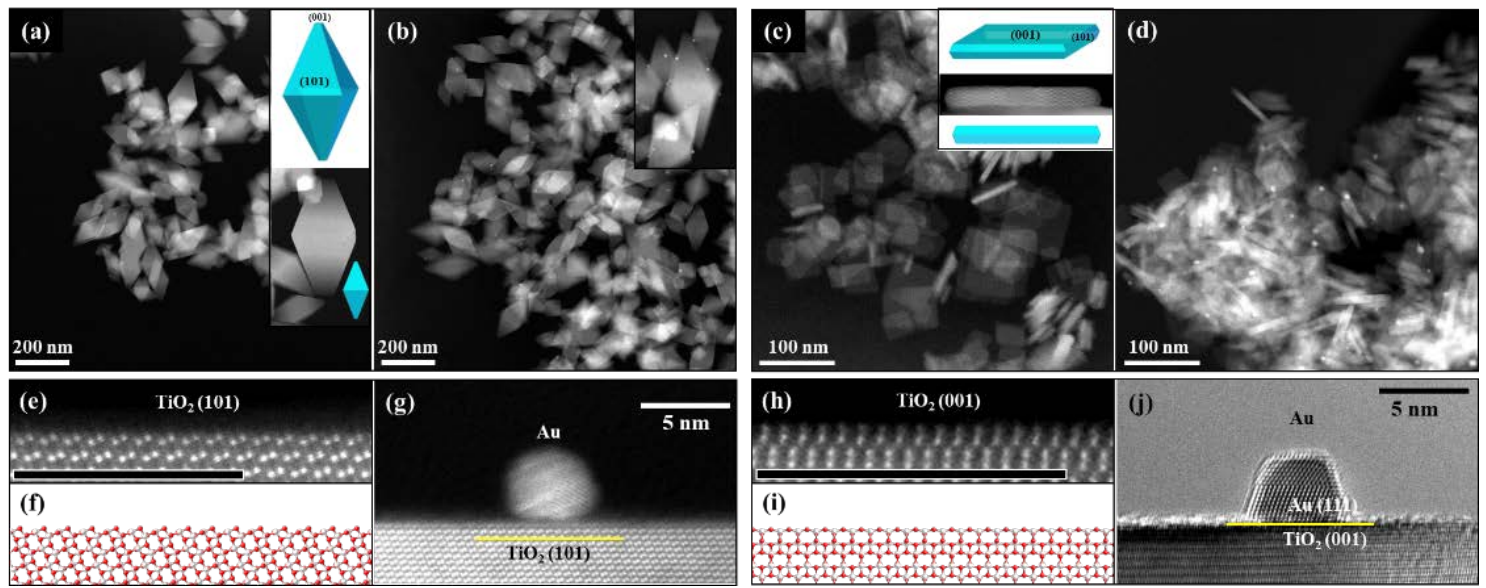

Figure 1. The typical interface of the Au- $\mathrm{TiO}_{2}$ catalysts. (a,b) Low-magnification HAADF-STEM images of $\mathrm{TiO}_{2}(101)$ supports (a) and Au-TiO 2 (001) catalysts, respectively. (c,d) Low-magnification HAADF-STEM images of $\mathrm{TiO}_{2}(101)$ catalysts (c) and $\mathrm{Au}-\mathrm{TiO}_{2}(001)$ catalysts (d), respectively. (e,f) High-magnification HAADFSTEM image (e) and the atomic structure $(\mathrm{f})$ of $\mathrm{TiO}_{2}(101)$ surface. $(\mathrm{g})$ High-magnification HAADF-STEM image shows the typical interface between Au NP and $\mathrm{TiO}_{2}$ (101) surface. (h,i) High-magnification HAADF-STEM image (h) and the atomic structure (i) of $\mathrm{TiO}_{2}(001)$ surface. (j) The TEM image shows the typical interface between $\mathrm{Au} \mathrm{NP}$ and $\mathrm{TiO}_{2}(001)$ surface. The scale bars both in (e) and (h) represent $5 \mathrm{~nm}$.

To explore how these two different MSIs affect the sintering behaviours of $\mathrm{Au}-\mathrm{TiO}_{2}$ catalysts, we performed in situ sintering experiments using $\mathrm{Au}-\mathrm{TiO}_{2}(001)$ and $\mathrm{Au}-\mathrm{TiO}_{2}$ (101) catalysts in ETEM. The samples were first heated to $500{ }^{\circ} \mathrm{C}$ at an oxygen environment $\left(5 \times 10^{-2} \mathrm{~Pa}\right)$, and then we carried out the in situ observation. It should be noted that under such environments, the surface organic contaminants introduced during synthesis could be removed, as evidenced by EELS analysis (Figure S7). It has been discussed by Wang et al. that the reduction level of the oxide-metal support could affect the sintering of suported metal $N P s^{[10]}$. Considering the $\mathrm{TiO}_{2}$ supports are easily reduced by the electron beam irradiation, a fairly low electron beam dose was used in our experiments $\left(\sim 1 \mathrm{~A} / \mathrm{cm}^{2}\right)$ to observe the intrinsic structure of $\mathrm{Au}-\mathrm{TiO}_{2}$ catalysts. ${ }^{[11]}$ Additionally, the reduction level of $\mathrm{TiO}_{2}$ surfaces in the experiments is also controlled by inducing low pressure oxygen environment, which compensates the electron beam induced oxygen-loss (reduction) in the $\mathrm{TiO}_{2}$ samples. ${ }^{[11]}$ The pressure is very low so that its effect on the sintering process can be negelected. During the sintering of Au$\mathrm{TiO}_{2}$ (101) catalysts, both PMC and OR processes were observed and a typical sintering process is shown in Figure 2. At initial, seven particles with the similar size $(\sim 8 \mathrm{~nm})$ are located on $\mathrm{TiO}_{2}$ (101) surface, labeled from (1) to (7), respectively (refer to Figure 2a). The projection area (PA) of each NP is estimated to quantify the NP size. These particles are separated by 0.80 to $4.36 \mathrm{~nm}$, except that particle (4) and (5) are connected. In $6 \mathrm{~s}$, the two particles (4) and (5)) got slightly closer with the enlargement of the contacting area, which indicates they started to coalesce. Meanwhile, the PA of particle (6), on the right side of the particle (5), changes from $66.5 \mathrm{~nm}^{2}$ to $61.4 \mathrm{~nm}^{2}$ (refer to Figure $2 \mathrm{a}$ and $2 \mathrm{~b}$ ), showing a typical ripening process. In the following process, the $\mathrm{Au}$ NPs (4) and (5) coalesced into one particle (Figure 2c, the dynamic process is shown in Figure S8), and the PA evolves from $149.1 \mathrm{~nm}^{2}$ to $160 \mathrm{~nm}^{2}$. The PA of particle (6) decreased smoothly from $61.4 \mathrm{~nm}^{2}$ to $23.4 \mathrm{~nm}^{2}$ (Figure 2e). One large particle (PA: $172.1 \mathrm{~nm}^{2}$ ) is left on the $\mathrm{TiO}_{2}$ (101) surface (Figure 2d) in the end (708 s). Interestingly, the interface of the sintered large particle is also very small (Figure $2 \mathrm{~d}$ ), and the IL/D is $\sim 0.45$, similar with the unsintered Au NP (0.44 to 0.58). This also indicates the observed $\mathrm{Au}-\mathrm{TiO}_{2}(101)$ interface (Figure 1a) is an intrinsic structure and 
confirms a weak interfacial interaction between $\mathrm{Au} \mathrm{NP}$ and $\mathrm{TiO}_{2}$ (101) surface. In addition, the sintering between particles (2) and (3) was also observed (Figure 2c-2d). The dynamic change of the projection area of each particle during the sintering process can be found in Figure 2e.
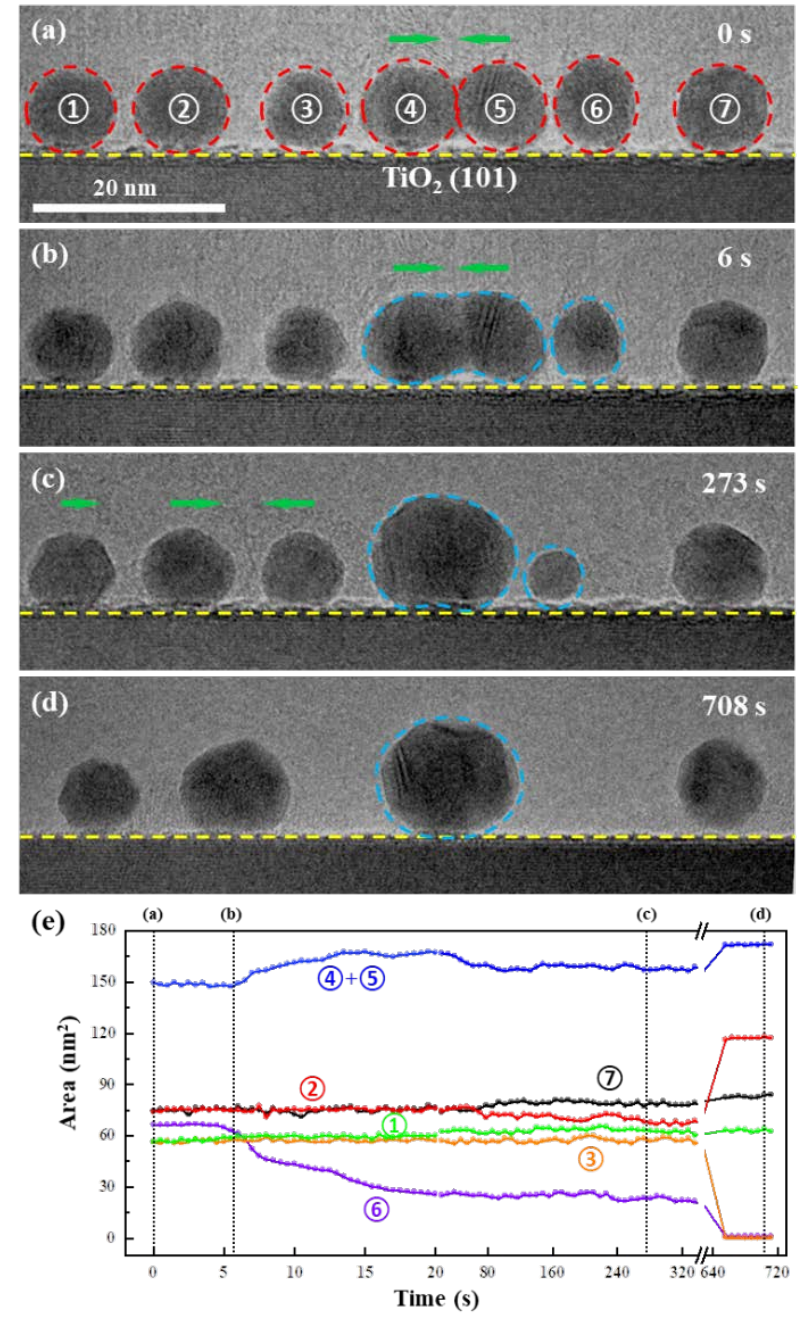

Figure 2. (a-d) The serial ETEM images show the sintering behavior of Au NPs on the $\mathrm{TiO}_{2}$ (101) surface. The red and blue dashed circles show the initial and changed states of the Au NPs. The green arrows show the moving direction of the Au NPs. The images are acquired at $500{ }^{\circ} \mathrm{C}$ and the oxygen pressure is $5 \times 10^{-2} \mathrm{~Pa}$. (e) Changes of the projection areas of Au NPs as a function of time. The time scale of $0-20 \mathrm{~s}$ is enlarged to show more details.

The situation was completely different on $\mathrm{TiO}_{2}(001)$ surface. In the same experimental conditions (temperature: $500{ }^{\circ} \mathrm{C}$; oxygen pressure: $5 \times 10^{-2} \mathrm{~Pa}$ ), neither notable PMC nor OR process of $\mathrm{Au}$ NPs was observed. A typical example is shown in Figures $3 a$ and $3 \mathrm{~b}$, through a top view. At the beginning (Figure $3 \mathrm{a}$ ), several $\mathrm{Au}$ NPs located on $\mathrm{TiO}_{2}$ nanosheets, which dominated by (001) surface, separated with small distances (The minimum distance is less than $0.46 \mathrm{~nm}$ ), which is the same order of magnitude as the sample in Figure 2. This time, these Au NPs were firmly attached to the substrate, in sharp contrast to the highly mobile Au NPs on $\mathrm{TiO}_{2}$ (101) surface. Even after $2297 \mathrm{~s}$, the sizes of the Au NPs did not show notable change (seeing Figure 3c), which shows a resistance of sintering of Au NPs on this surface. The side view images also confirms this conclusion and show strong interaction between $\mathrm{Au}$ NPs and $\mathrm{TiO}_{2}(001)$ surface (Figures $3 d$ and 3e). Since the $\mathrm{TiO}_{2}$ nanosheets slightly rotated due to the damage of supporting carbon membrane, the locations of the $\mathrm{Au}$ NPs in Figure $3 \mathrm{~b}$ are slightly different with those in Figure $3 \mathrm{a}$. The Au NPs on (001) surface (between 10 and $40 \mathrm{~nm}^{2}$ ) are smaller than those on (101) surface (between 40 and $160 \mathrm{~nm}^{2}$ ). Normally, smaller NPs are considered to be easier to sinter due to their larger surface energies. The fact that the smaller An NPs on (001) surface are more stable than the larger ones on (101) surface further verifies the sintering resistance of (001) surface. Note that the different size distribution of the Au NPs on the two surfaces could also be understood as a result from the facet-dependent sintering behaviour.
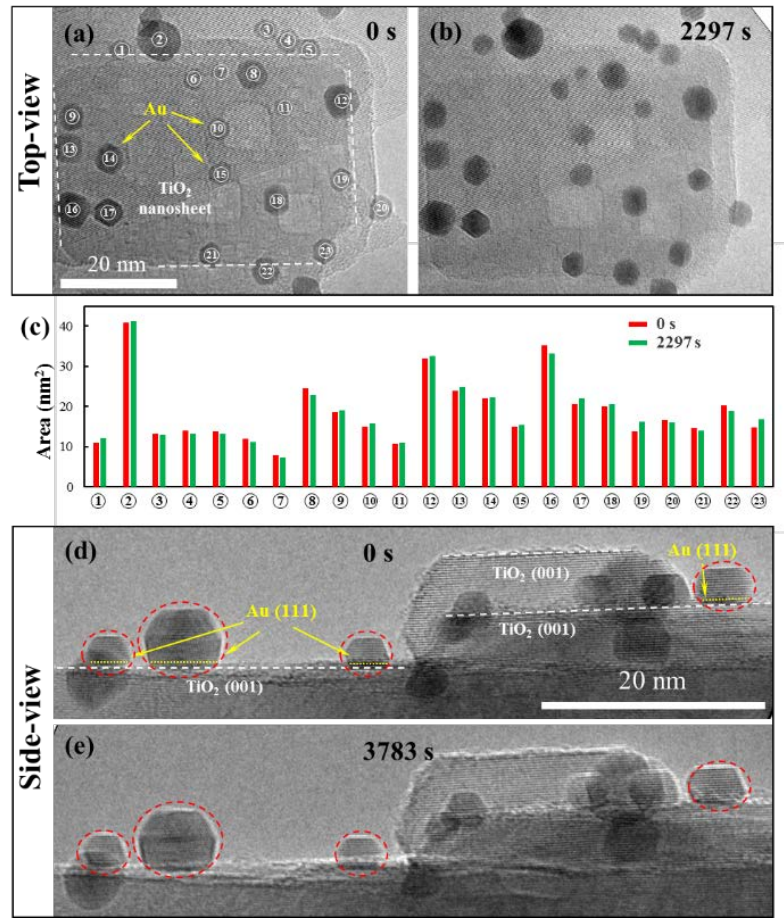

Figure 3. The serial TEM images show the sintering behavior of $A u$ nanoparticles on the $\mathrm{TiO}_{2}$ (001) surface, both from top view (a-b) and side view (d-e). The red dashed circles show the initial states of the Au NPs. The images are acquired at $\sim 500{ }^{\circ} \mathrm{C}$ and the oxygen pressure is $\sim 5 \times 10^{-2} \mathrm{~Pa}$. (c) Statistics of the projection areas of the Au NPs in (a) and (b).

To understand this facet dependent sintering behavior, DFT calculations have been performed. The adsorptions of Au NP on the two surfaces $\left(\mathrm{TiO}_{2}(001)\right.$ and (101)) were studied firstly. $\mathrm{A} \mathrm{Au}_{20}$ cluster of pyramid structure with (111) surfaces was used as the model system ${ }^{[12]}$. For $\mathrm{Au}_{20}$ cluster, the adsorption energies on (001) surface $(-2.28 \sim-3.62 \mathrm{eV})$ is much larger than those on (101) surface $(-0.30 \sim-0.47 \mathrm{eV})$. It is consistent with the TEM observations that the preferential relationship exists between $\mathrm{Au}$ (111) $-\mathrm{TiO}_{2}(001)$ interface, but not for $\mathrm{Au}-\mathrm{TiO}_{2}$ (101) interface. Further, the activation barriers in the two sintering mechanisms were investigated. The rate of $\mathrm{PMC}$ is mainly determined by the potential energy surface (PES) for the $\mathrm{Au}-\mathrm{TiO}_{2}$ interface. In this work, we estimate the roughness of the PES by calculating the adsorption energies $\left(E_{a d s}\right)$ of $\mathrm{Au}_{20}$ on different adsorption sites of $\mathrm{TiO}_{2}$ surfaces. The results show that the differences among $E_{a d s}$ on different sites of $\mathrm{TiO}_{2}(101)$ surface are quite small (within 0.18 
$\mathrm{eV}$ ), which indicates a rather flat PES. While, a rough PES is found for $E_{\text {ads }}$ on $\mathrm{TiO}_{2}(001)$ surface ( $E_{\text {ads }}$ differences reach 1.34 $\mathrm{eV})$. This explains the prevented PMC of Au NPs on $\mathrm{TiO}_{2}(001)$ surface and the mobility of $\mathrm{Au} \mathrm{NPs}$ on $\mathrm{TiO}_{2}$ (101) surface. The results are given in Figure 4. The same conclusion is also acquired from the DFT calcluations of $\mathrm{FCC} \mathrm{Au}_{79}$ cluster on the two surfaces (refer to Figure S9). In both sizes, the PES of $\mathrm{TiO}_{2}(001)$ surface is much rougher than that of $\mathrm{TiO}_{2}$ (101) surface, which indicates that the sizes of the NPs have little effects on the facetdependent sintering behaviour.

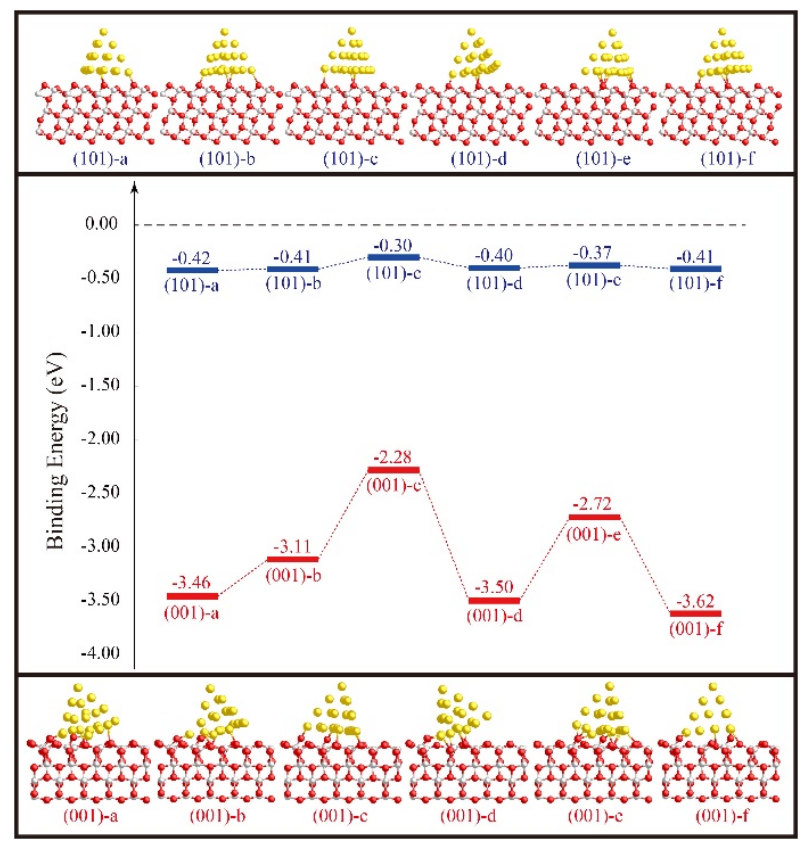

Figure 4. The adsorption energies and configurations of a $\mathrm{Au}_{20}$ cluster on different adsorption sites of $\mathrm{TiO}_{2}(101)$ surface and $\mathrm{TiO}_{2}(001)$ surface, which shows the roughness of the potential energy surface of a Au NP on the two surfaces.

OR is caused by the net rate of the diffusion of the adatom on the substrate (AoS) from smaller NP to bigger NP. ${ }^{[13]}$ Apparently, the formation of the AoS is a prerequisite condition to OR. As shown in Figure 5 , it is rate limited by a two-step interfacecontrolled detachment process. In step one, a metal atom moves off the NP through a transition intermediate state, refereed as a "monomer on the particle" (MoP) by Wynblatt and Gjostein, and becomes an adatom near the particle (AnP). ${ }^{[13]}$ The MoP is defined as a metal atom at the low-coordinated edge site of the NP that interacts weakly to the metal NP but strongly to the support. ${ }^{[14]}$ The activation barrier in this step comes mainly from the energetic difference between a MoP and an AnP, as shown below:

$$
E_{a}^{1}=E_{\text {ads }}^{A n P}-\left(E_{\text {ads }}^{M o P}+E_{b}\right)
$$
where $E_{b}$ is the metal-metal bonding energy, and $E_{a d s}^{M o P} / E_{a d s}^{A n P}$ is the adsorption energy of MoP/AnP on the support surface. ${ }^{[14]}$ $E_{a d s}^{M o P}$ is coordination number dependent. As the coordination number of MoP is close to zero, the difference between $E_{a d s}^{M o P}$ and $E_{a d s}^{A n P}$ can be considered small. Therefore, $E_{a}^{1}$ is mainly dependent on $E_{b}$ which is independent on the MSI. In step two, the AnP diffuses away from the NP to become an AoS. The activation barrier in this step $\left(E_{a}^{2}\right)$ is determined by the diffusion barrier of atdatom $\left(E_{m}\right)$ on the support surface. Thus, the MSI mainly affects the formation of AoS through $E_{m}$. The pathways of the detachment processes of $\mathrm{Au}$ on anatase $\mathrm{TiO}_{2}$ surfaces are shown in Figure 5. On $\mathrm{TiO}_{2}$ (101) surface, the gold atom prefers to adsorb on the bridge site of the surface with the adsorption energy of $0.54 \mathrm{eV}$. The $E_{m}^{101}$ is only $0.19 \mathrm{eV}$, which can be easily overcome at low temperature. On the other hand, the adsorption energy of a gold adatom on $\mathrm{TiO}_{2}(001)$ surface is $-2.74 \mathrm{eV}$ and the $E_{m}^{001}$ is much higher $(1.31 \mathrm{eV})$. Thus, the AnP is difficult to move and to form AoS on the $\mathrm{TiO}_{2}(001)$ surface. Without the formation of AoS, the OR could not occur. On the contrary, the easily formed AoS on $\mathrm{TiO}_{2}(101)$ surface could help the OR to take place. Thus, the experimental observations are explained and it concludes that strong MSI can prevent OR process, while weak MSI can promote OR process.

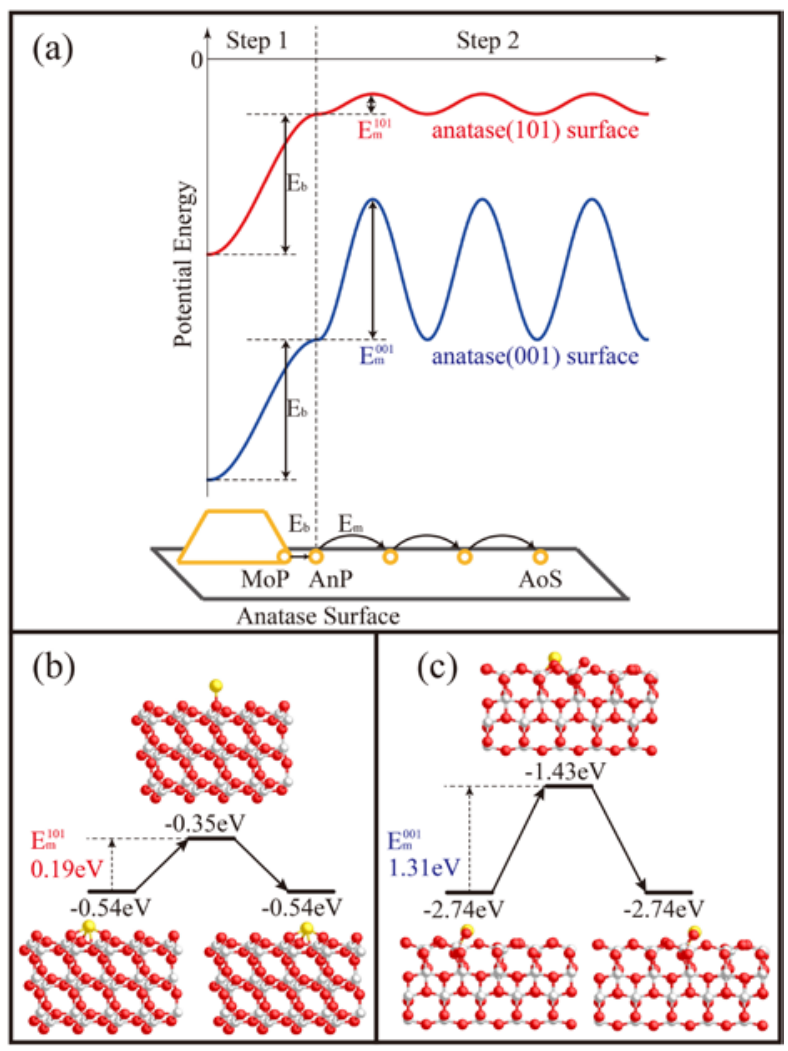

Figure 5. (a) A schematic representation of the formation process of a Au adatom on the support $\mathrm{TiO}_{2}$ anatase surface. (b, c) The energy pathway of the diffusion of a Au adatom on the $\mathrm{TiO}_{2}(101)$ surface and $\mathrm{TiO}_{2}(001)$ surface.

In conclusion, through Cs-corrected STEM and ETEM, we revealed a facet-dependent sintering behavior of $\mathrm{Au}-\mathrm{TiO}_{2}$ nanocatalysts. Through analyzing the interface structure, we found a preferential relationship could be formed at $\mathrm{Au}-\mathrm{TiO}_{2}(001)$ interface but not at $\mathrm{Au}-\mathrm{TiO}_{2}$ (101) interface, which indicates $\mathrm{Au}$ NPs attached on $\mathrm{TiO}_{2}(001)$ surface more firmly than on $\mathrm{TiO}_{2}$ (101) surface. During the in situ heating experiments, the sintering of Au NPs through both the OR and the PMC mechanisms was observed on $\mathrm{TiO}_{2}$ (101) surface. Interestingly, the sinteringresistant $\mathrm{Au}$ NPs on $\mathrm{TiO}_{2}$ (001) was unveiled. Through DFT calculations, the facet-dependent sintering behavior was fully explained by considering the adsorption energies of Au NP and diffusion barriers of $\mathrm{Au}$ adatom on different surfaces. This work not only gives the clear evidence of the atomic observation and theoretical understanding of the substrate effects on the sintering 
of supported NPs, but paves the way for the rational design of efficient sintering-resistant catalysts.

\section{Acknowledgements}

We acknowledge the financial support of National Natural Science Foundation of China (51390474, 91645103, 11574340, 21773287, 11604357 and 11327901) and the Ministry of Science and Technology of China (No. 2016YFE0105700). B.Z. thanks for Natural Science Foundation of Shanghai (16ZR1443200). We also thank for Special Program for Applied Research on Super Computation of the NSFC-Guangdong Joint Fund (the second phase) under Grant No. U1501501.

Keywords: sintering $\bullet$ Ostwald ripening $(\mathrm{OR}) \cdot$ particle migration and coalescence $(\mathrm{PMC}) \cdot$ metal-support interaction $(\mathrm{MSI}) \cdot$ in situ TEM • Au-TiO 2

[1] a) M. Haruta, N. Yamada, T. Kobayashi, S. lijima, J. Catal. 1989, 115 301-309; b) T. Akita, M. Kohyama, M. Haruta, Acc. Chem. Res. 2013, 46 1773-1782; c) G. Prieto, J. Zecevic, H. Friedrich, K. P. de Jong, P. E. de Jongh, Nat. Mater. 2013, 12, 34-39; d) M. Y. Duan, J. Yu, J. Meng, B. E. Zhu, Y. Wang, Y. Gao, Angew. Chem. Int. Ed. 2018, 57, 6464-6469.

[2] a) M. Haruta, Catal. Today 1997, 36, 153-166; b) M. S. Chen, D. W. Goodman, Science 2004, 306, 252-255.

[3] a) T. W. Hansen, A. T. Delariva, S. R. Challa, A. K. Datye, Acc. Chem Res. 2013, 46, 1720-1730; b) C. T. Campbell, Acc. Chem. Res. 2013, 46, 1712-1719.

[4] a) R. Ouyang, J. X. Liu, W.-X. Li, J. Am. Chem. Soc. 2013, 135, 17601771; b) E. D. Goodman, J. A. Schwalbe, M. Cargnello, ACS Catal. 2017, 7, 7156-7173.

[5] a) A. T. DelaRiva, T. W. Hansen, S. R. Challa, A. K. Datye, J. Catal. 2013, 308, 291-305; b) C. T. Campbell, Z. Mao, ACS Catal. 2017, 7 8460-8466; c) J. A. Farmer, C. T. Campbell, Science 2010, 329, 933-936.

[6] a) H. Sulei, L. Wei-Xue, ChemNanoMat 2018, 4, 510-517; b) S. L. Hemmingson, C. T. Campbell, ACS Nano 2017, 11, 1196-1203; c) C. W. Han, P. Majumdar, E. E. Marinero, A. Aguilar-Tapia, R. Zanella, J. Greeley, V. Ortalan, Nano Lett. 2015, 15, 8141-8147.

[7] a) S. B. Simonsen, I. Chorkendorff, S. Dahl, M. Skoglundh, J. Sehested, S. Helveg, J. Am. Chem. Soc. 2010, 132, 7968-7975; b) S. R. Challa, A T. Delariva, T. W. Hansen, S. Helveg, J. Sehested, P. L. Hansen, F. Garzon, A. K. Datye, J. Am. Chem. Soc. 2011, 133, 20672-20675; c) M. A. Asoro, P. J. Ferreira, D. Kovar, Acta Mater. 2014, 81, 173-183; d) K. J. Hu, S. R. Plant, P. R. Ellis, C. M. Brown, P. T. Bishop, R. E. Palmer, J. Am. Chem. Soc. 2015, 137, 15161-15168; e) Y. Jiang, H. B. Li, Z. M. Wu W. Y. Ye, H. Zhang, Y. Wang, C. H. Sun, Z. Zhang, Angew. Chem. Int Ed. 2016, 55, 12427-12430; f) T. E. Martin, P. L. Gai, E. D. Boyes, Chemcatchem 2015, 7, 3705-3711; g) D. S. Su, B. S. Zhang, R. Schlogl, Chem. Rev. 2015, 115, 2818-2882; h) Y. Jiang, Z. Zhang, W. Yuan, X. Zhang, Y. Wang, Z. Zhang, Nano Res. 2017, 11, 42-67; i) R. van den Berg, T. E. Parmentier, C. F. Elkjaer, C. J. Gommes, J. Sehested, S Helveg, P. E. de Jongh, K. P. de Jong, ACS Catal. 2015, 5, 4439-4448; j) C. Aydin, J. Lu, N. D. Browning, B. C. Gates, Angew. Chem. Int. Ed. 2012, 51, 5929-5934; k) M. Tang, B. E. Zhu, J. Meng, X. Zhang, W. T. Yuan, Z. Zhang, Y. Gao, Y. Wang, Materials Today Nano. 2018, 1, 4146.

[8] W. T. Yuan, J. Meng, B. E. Zhu, Y. Gao, Z. Zhang, C. H. Sun, Y. Wang, Chem. Mater. 2018, 30, 288-295.

[9] C. H. Sun, S. C. Smith, J. Phys. Chem. C 2012, 116, 3524-3531.

[10] Y. G. Wang, Y. Yoon, V. A. Glezakou, J. Li, R. Rousseau, J. Am. Chem. Soc. 2013, 135, 10673-10683.
[11] a) Y. Kuwauchi, H. Yoshida, T. Akita, M. Haruta, S. Takeda, Angew. Chem. Int. Ed. 2012, 51, 7729-7733; b) W. T. Yuan, Y. Wang, H. B. Li H. L. Wu, Z. Zhang, A. Selloni, C. H. Sun, Nano Lett. 2016, 16, 132-137.

[12] J. Li, X. Li, H. J. Zhai, L. S. Wang, Science 2003, 299, 864-867.

[13] P. Wynblatt, N. A. Gjostein, Prog. Solid State Chem. 1975, 9, 21-58.

[14] S. C. Parker, C. T. Campbell, Phys. Lett. B 2007, 75, 035430. 


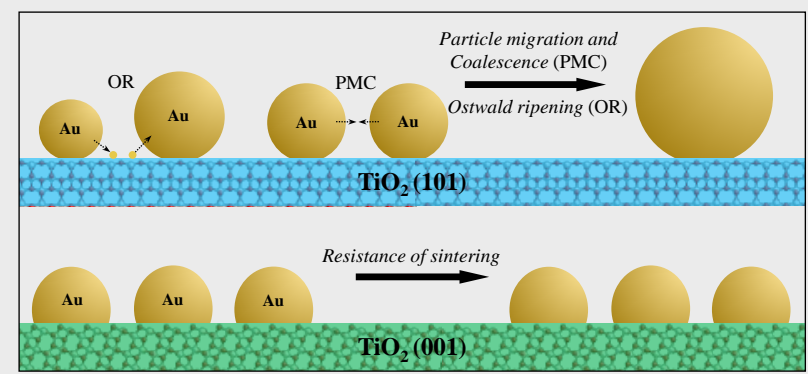

Wentao Yuan, ${ }^{[a]+}$ Dawei Zhang, ${ }^{[b]+}$ Yang $\mathrm{Ou},{ }^{[a]} \mathrm{Ke}$ Fang, ${ }^{[a]}$ Beien Zhu, ${ }^{*[b]}$ Hangsheng Yang, ${ }^{[a]}$ Thomas $W$. Hansen, ${ }^{[c]}$ Jakob B. Wagner, ${ }^{[c]} Z e$ Zhang, ${ }^{[a]}$ Yi Gao $^{\star[b]}$ and Yong Wang ${ }^{\star[a]}$

Page No. - Page No.

Direct in situ TEM visualization and insight of the facet-dependent sintering behaviours of $\mathrm{Au}$ on $\mathrm{TiO}_{2}$

Completely different sintering behaviours of Au nanoparticles on distinct anatase $\mathrm{TiO}_{2}$ surfaces are unveiled by environmental TEM 